Document downloaded from:

http://hdl.handle.net/10251/152818

This paper must be cited as:

Mas Verdú, F.; Ortiz Miranda, D.; García Alvarez-Coque, JM. (2016). Examining organizational innovations in different regional settings. Journal of Business Research. 69(11):5324-5329. https://doi.org/10.1016/j.jbusres.2016.04.132

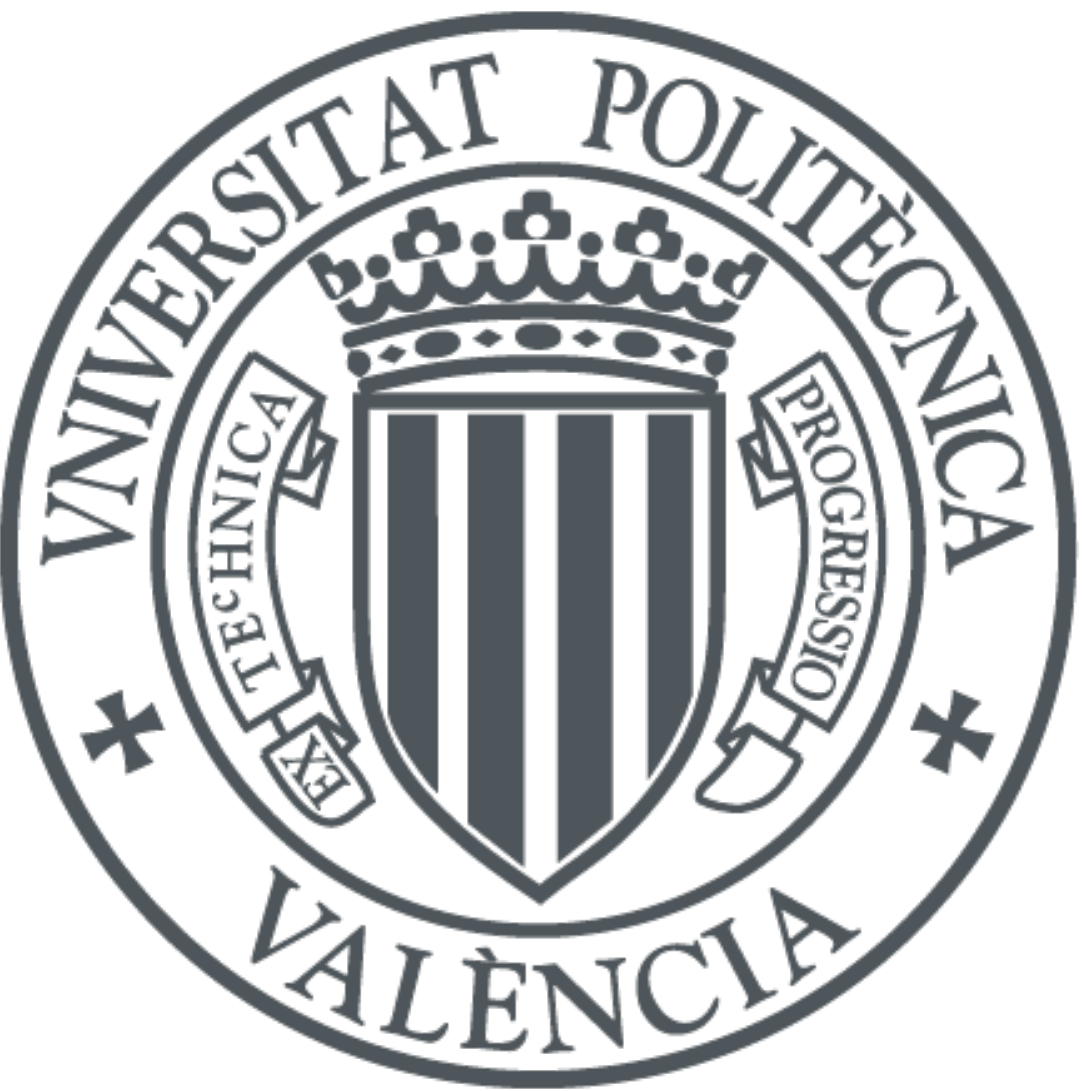

The final publication is available at

https://doi.org/10.1016/j.jbusres.2016.04.132

Copyright Elsevier

Additional Information 


\title{
Examining organizational innovations in different regional settings
}

\author{
Francisco Mas-Verdú, Universitat Politècnica de València \\ Dionisio Ortiz-Miranda, Universitat Politècnica de València \\ José María García Álvarez-Coque, Universitat Politècnica de València
}

Submission: January 2016

Revision: April 2016

The authors thank Norat Roig-Tierno, ESIC Business and Marketing School and Valencian International University (VIU) for his careful reading and suggestions, especially in the methodology section. We wish to thank the Project AGL2015-65897C3-3-R funded by the Ministry of Economy and Competitiveness, for its support for this research. Send correspondence to Francisco Mas-Verdú, Department of Economics and Social Sciences, Universitat Politècnica de València, Camino de Vera, s/n, 46022 Valencia, Spain (fmas@upvnet.upv.es). 


\begin{abstract}
A key element of regional growth is its ability to transform knowledge into innovation. This research combines a group of indicators which define innovative regions with a rurality versus urbanization typology, in order to formulate guidelines to facilitate the emergence of higher levels of organizational innovation. Three main findings stem from this work. First, rurality does not appear prohibitive to the achievement of organizational innovation. Second, in regions with low levels of tertiary education, a combination of high levels of collaboration among small- and mediumsized enterprises, and public investment in research and development facilitates significant rates of organizational innovation. Third, in general, collaboration among firms promotes organizational innovation. The results of this research are in line with those from other studies in the sense that regions with internal and external networks show enhanced growth and innovation capacities.
\end{abstract}

Keywords: Organizational innovation; urban-rural typology; collaboration; R\&D expenditure; tertiary education 


\section{Introduction}

The competitiveness of regions depends on their ability to attract and retain businesses with high growth potential so as to maintain and improve the quality of life of their citizens (Huggins, 2003). This competitiveness can vary in space depending on certain factors (Audretsch \& Keilbach, 2004) including both tangible (human natural resources, etc.) and also intangible resources which promote regional growth and competitiveness (Camagni \& Capello, 2013). In this sense, a key source of growth is the capacity of regions to generate, accumulate, and diffuse knowledge which they can transform into innovations (Antonelli et al., 2011). Specifically, the literature on innovation systems emphasizes the role of knowledge flows through the territory as critical for effective innovation (Cooke et al., 2011).

The notion of innovation and its incorporation into economic activity has changed dramatically since the mid-2000s. The elements at the core of innovation can be both tangible and intangible and consist of information transferred to the customer. The emphasis has shifted from the physical characteristics of products to the value that the customer experiences (Prahalad \& Ramaswamy 2004; Vargo \& Lusch, 2008), which is increasing the importance of non-technological and, especially, organizational innovations. Also, innovations are no longer developed only within organizational boundaries; innovation frequently is the result of collaboration involving an extensive network of external agents (suppliers, partners, customers) (Chesbrough, 2003). In other words, the innovation potential of firms depends not only on these firms' internal resources but also on each firm's ability to combine its internal capacities with the resources available in its territorial environment. Hence the need to take account of the characteristics of each region in order to understand the innovation process. 
Studies seem to assume that territory matters for the innovation process.

Although different methods exist to characterize the territorial setting, a useful means of differentiating regional growth and development paths is to adopt a rural-urban area typology (Naldi et al., 2015). This allows a synthesis of various factors (economic, spatial, and social) relevant to innovation.

The aim of this study is to combine the characteristics of the region (in terms of rurality and urbanization) with indicators of innovative regions based on the Regional Innovation Scoreboard (European Commission, 2014) framework, in order to identify patterns which give rise to higher degrees of organizational innovation.

The study's structure is as follows. Section 2 reviews the literature on the characteristics of innovative regions. Section 3 describes the research method and the key features of the qualitative comparative analysis (QCA). Section 4 presents the results, and section 5 discusses the main results and some final considerations.

\section{Theoretical background}

\subsection{Innovation along the urban-rural typology}

In studying how regional characteristics influence the innovation process, several scholars pay particular attention to the concentration-dispersion of population and activities continuum. According to the literature, agglomeration in urban regions enables innovation. Indeed, Duranton and Puga (2004) argue that three main mechanisms drive agglomeration economies: (i) sharing of fixed costs and risk, (ii) matching in the labor market, and (iii) learning due to knowledge spillovers and human capital accumulation (Naldi et al., 2015).

The RIS approach (Cooke et al., 2004) allows for better consideration of the social dimension of innovation, the relevance of knowledge flows within and between 
actors (innovators, customers, competitors, public bodies, technology transfer, science and research, education), and the ties among them (Guillaume \& Doloreux, 2011), so that spatial proximity and actor density become innovation enablers. Thus, theoretically metropolitan areas and urban agglomerations with high-tech industries, high levels of research and development (R\&D) expenditure, and a highly educated workforce should be more innovative (Crescenzi \& Rodriguez-Pose, 2011). Similarly, Crescenzi (2005) finds an outstanding role of accessibility (reflecting the probability of contacts between people) for favoring regional innovation.

On the other hand, less populated and less dense regions (rural regions) suffer from constraints such as lack knowledge-intensive companies, supporting infrastructures, and specialized services (Huggins \& Johnston, 2009), and low density of companies (Doloreux \& Dionne, 2008). Furthermore, innovation in sparsely populated regions often relies on their connections to urban areas; thus, rural and peripheral areas which are geographically distant from growth centers and have lower levels of agglomeration and thus fewer possibilities to access external knowledge (Naldi et al., 2015).

P1. Densely populated regions present higher levels of organizational innovation.

\subsection{Collaboration with other agents}

The literature proposes a range of reasons to explain why firms collaborate with other firms or entities (Howells, 2006). Firms can collaborate with: (i) research institutions or universities for the development of products or services, and (ii) companies in the same sector (e.g., suppliers or customers) to incorporate knowledge into the firm's value chain (Lasagni, 2012). Some research associates the concept of absorptive capacity (AC) with innovation per se and with the level of the firm's external 
collaboration activity. AC refers to the ability of the firm to "identify, assimilate, and exploit knowledge from the environment" (Cohen \& Levinthal, 1989, p. 589), and highlights that companies cannot take advantage of external knowledge flows merely by exposing themselves to that knowledge. Several studies (Escribano et al., 2009; Fabrizio, 2009; Un \& Asakawa, 2015) point to the positive relationship between AC and innovation and external cooperation.

Collaboration can be a broad or an interactive activity. Collaboration is described as broad when the process involves a wide spectrum of actors (technology centers, universities, companies, organizations) working together on a particular field of research and technological development. This joint collaboration includes bilateral relations between actors and also the integration of companies in R\&D networks to create, disseminate, and exploit innovations and new knowledge. Alternatively, collaboration between agents to generate innovations can be the result of an interactive process (Kline \& Rosenberg, 1986). Collaboration provides access to additional resources to increase the degree of novelty of the invention and increase its implementation rate (Bouncken et al., 2015). Thus, R\&D collaborations do not replace but rather complement and strengthen internal R\&D efforts (Lin et al., 2012).

Specifically, the institutional infrastructure in territorial environments (RoigTierno et al., 2015) provides a remarkable range of possibilities for collaboration among the agents in the innovation system, to identify, adjust, and adapt knowledge (Castrogiovanni et al., 2012). Additionally, this institutional infrastructure both provides direct services to firms, and acts as an intermediary to strengthen the interaction and collaboration among companies (Inkinen \& Suorsa, 2010).

Cooperation can involve transaction costs associated with the exchange of information, and, seemingly, no linear relationship exists between the intensity of 
cooperation and the innovative outcomes ( $\mathrm{Wu}, 2014)$. The relationship between these two variables appears to take the form of an inverted $\mathrm{U}$ : although at any given time high levels of cooperation and information exchange result in highly innovative performance, excess collaboration can introduce the risk of opportunism among cooperating agents. The literature (Hagedoorn, 2002; Garcia-Alvarez-Coque et al., 2015) tends to emphasize some particular advantages of collaboration such as market diversification, cross-fertilization of knowledge, access to new external sources of information, and the benefits derived from shared R\&D costs.

The above discussion suggests that collaboration and R\&D partnerships are advantageous for the generation of innovations.

P2: Regions hosting small and medium sized enterprises (SMEs) which collaborate closely show high levels of innovation.

\subsection{Availability of highly skilled workers}

The literature generally argues for the existence of a significant positive relationship between economic growth and human capital (Bodman \& Le, 2013; Hall \& Jones, 1999). Specifically, the region's factor endowments influence its productive specialization. Thus, territories with supplies of high skilled human capital tend to generate and attract industries with high potential for innovation. In turn, human capital complements (Caselli \& Coleman, 2006) factors such as physical capital.

Several authors (Afonso, 2012; Ciccone \& Papaioannou, 2009) highlight the role human capital plays in achieving structural change and place innovative activities at the center of territorial competitiveness. The accumulation of human capital acts in two ways. On the one hand, education increases management skills, improves knowledge, and therefore, facilitates access to new business opportunities related to innovative 
activities (Justman \& Teubal, 1991). On the other hand, the implementation of innovation requires a certain level of human capital (Vandenbussche et al., 2006).

Improved access to new channels of information, and ultimately, increased productivity of workers have a strong connection with education and human capital stock. Both the formal education system and the territorial environment affect the acquisition of new skills and capabilities (Hanushek \& Woessmann, 2008). Regions with a supply of highly skilled workers develop and attract innovation-based industries. P3: Regions with a good supply of highly skilled workers have a high innovation index.

\section{4. $R \& D$ expenditure}

A remarkable number of theoretical and empirical contributions - from classical studies (Arrow, 1962) to some of the most recent work by Coe et al. (2009) or O’Mahony and Vecchi (2009)—report the positive effect of R\&D on growth, productivity, and innovation in firms and in territories. In developed regions, $R \& D$ is one of the main factors determining productivity, economic growth, and innovation. Most $R \& D$ is conducted by private firms. Government supports these firms' R\&D activities by enacting laws to protect intellectual property rights, and by providing a good research infrastructure (from educational establishments to public research institutions or entities engaged in knowledge transfer).

However, government also provides financial assistance for R\&D: (i) by providing funding for the public research system, and for the education of highly qualified human capital, and (ii) through tax incentives and direct subsidies for R\&D. No consensus exists on the nature and role of public funding: some studies highlight the complementarity between public and private $R \& D$, while others find a substitutive 
relationship between these two sources of research funding (see David et al., 2000 for a review of the literature).

The above arguments lead to the following propositions.

P4: Regions with high levels of public expenditure on R\&D have significant rates of organizational innovation.

P5: Regions with high levels of private expenditure on R\&D have high rates of organizational innovation.

\section{Method and data}

Explaining organizational innovation from a territorial perspective requires a multidimensional approach which provides a qualitative and quantitative view of the conditions which promote organizational innovation. In the context of the present study, conditions refer to spatial factors, innovation policies, collaboration culture, and a prevalence of higher education among the region's population. The application of QCA reveals patterns of association or causal settings which validate the existence of such relations (Schneider \& Wagemann, 2010).

QCA uses set theory which draws on the influence of certain elements on a specific outcome, that is, on how these elements combine with each other (Ragin, 2008; Fiss, 2009). QCA enables systematic case comparison to explain a specific outcome. This approach differs from traditional statistical methods which draw on the individual elements per se (Ragin, 2008; Ragin \& Fiss, 2008). QCA analyzes relationships in terms of necessity or sufficiency to explain the analyzed outcomes. According to Ragin (2008), QCA consists of two groups of variables: the causal conditions which explain the outcome, and the outcome condition. A condition is necessary if that condition is present every time the outcome is present. In other words, the outcome is impossible 
without that condition. A condition is sufficient if the presence of the condition by itself causes the outcome. Ragin developed fuzzy-set QCA (fsQCA), which allows scaling of the explanatory factors or conditions in an interval $\{0,1\}$. The definition of the different thresholds builds on the calibration of the conditions and the outcome, with breakpoints for the study to qualify an attribute or condition as "high" or "low."

The fsQCA's original purpose is to analyze small and medium databases (e.g. < 50 cases) (Collier, 1993) but no mathematical limitation impedes working with larger databases (Ragin, 1987, 2006; Ragin \& Fiss, 2008; Woodside \& Zhang, 2012). The fsQCA method has a wide range of applications in the social sciences, with some contributions on the comparative performance of firms and countries related to hightech activities (Fiss, 2011; Schneider et al., 2010). The present study uses fsQCA to provide insights into organizational innovation from a regional perspective.

As part of this research, the construction of the different causal combinations establishes whether the EU regions, depending on the type of causal relationship, achieve a low or a high rate of organizational innovation. Some regional characteristics identified in the previous conceptual framework are helpful for understanding the degree of organizational innovation (iorg). For the QCA analysis, the outcome variable is the degree of iorg. Five indicators represent regional causal conditions in the $140 \mathrm{EU}$ regions analyzed: the extent of tertiary education (Edu), public and private $R \& D$ spending (Rdp and Rdb respectively), degree of SMEs' collaboration with other firms (Col), and degree of rurality which summarizes spatial attributes (Rural). Table 1 describes the regional conditions, most of which appear in the Regional Innovation Scoreboard (2014).

To measure the degree or rurality, the study draws on EUROSTAT methodology for the spatial delimitation of rural and urban regions using population density 
(EUROSTAT, 2010). EUROSTAT classifies NUTS3 (Nomenclature of Units for Territorial Statistics) areas as predominantly rural (PR, more than $50 \%$ of population living in rural areas), intermediate (IR, rural population accounts for 50\%-20\%) and predominantly urban (PU, less than $20 \%$ of rural population). In order to combine with Regional Innovation Scoreboard data, the analysis in this study is at the NUTS2 level. This procedure requires taking account of the percentage of regional gross value added in each NUTS2, from PR, IR, and PU NUTS3.

As already noted, fsQCA requires calibration of the process conditions and the outcome. Ragin (2008) identifies three thresholds for the presence or absence of the conditions in continuous variables. Ragin defines these thresholds as: entirely within the set 0.95 , entirely outside the set 0.05 , and the point of maximum ambiguity 0.5 . In this study the 90th percentile and 10th percentile are the cutoffs to determine the presence or absence of the conditions, and the median serves to establish the point of maximum ambiguity (Misangyi \& Acharya, 2014). To calibrate the rural condition, the cutoff points are 80 (fully in), 50 (point of maximum ambiguity), and 20 (fully out). Table 1. Description of causal conditions

\begin{tabular}{|c|c|}
\hline Edu & $\begin{array}{l}\text { Percentage of people aged between } 30 \text { and } 34 \text { years } \\
\end{array}$ \\
\hline Rdb & Total private investment in R\&D (percentage of \\
& regional GDP) \\
\hline Rdp & Total investment in R\&D by public sector and higher \\
& education institutions (percentage of regional GDP) \\
\hline Col & Percentage of SME collaborating in innovation \\
& projects with other agents \\
\hline Rural & Degree of rurality in NUTS2 regions based on the \\
\hline
\end{tabular}




\begin{tabular}{|l|l|}
\hline & $\begin{array}{l}\text { percentage of GVA coming from predominantly rural areas in } \\
\text { the region. }\end{array}$ \\
\hline
\end{tabular}

\section{Results}

In line with the conceptual framework, and rather than examining the impact of individual conditions, this study looks at interdependencies that rely on a number of conditions coexisting in a region. A condition is necessary if the consistency threshold exceeds the value of 0.90 (Ragin, 2008; Schneider et al., 2010). In Table 2, where the symbol $(\sim)$ means the absence of a condition, no single condition explains the presence of high iorg in the regions under study

Table 2. Analysis of necessary conditions for presence of organizational innovation

\begin{tabular}{|c|c|c|}
\hline Conditions tested & Consistency & Coverage \\
\hline Edu & 0.528642 & 0.534805 \\
\hline$\sim \mathrm{Edu}$ & 0.530656 & 0.626966 \\
\hline $\mathrm{Rdp}$ & 0.672410 & 0.719072 \\
\hline$\sim \mathrm{Rdp}$ & 0.408593 & 0.454116 \\
\hline $\mathrm{Rdb}$ & 0.668270 & 0.745600 \\
\hline$\sim \mathrm{Rdb}$ & 0.409823 & 0.436643 \\
\hline $\mathrm{Col}$ & 0.673976 & 0.739595 \\
\hline$\sim \mathrm{Col}$ & 0.363728 & 0.393822 \\
\hline Rural & 0.256545 & 0.562837 \\
\hline$\sim$ Rural & 0.793354 & 0.575288 \\
\hline
\end{tabular}

Note: $(\sim)$ absence of the condition. Calculated fsQCA 2.5 (Ragin \& Davey, 2014). 
The analysis of sufficiency conditions focuses on the presence of iorg in the EU regions. The model identifies possible causal configurations which explain a high iorg as follows:

iorg $=\mathrm{f}(\mathrm{edu}, \mathrm{rdp}, \mathrm{rdb}, \mathrm{col}$, rural $)$

Table 2 presents the causal configurations that lead to high rates of iorg in the regions. Specifically, this study applies a consistency cut-off value of 0.9 in the "truth table." The whole model has a consistency of 0.92 which means the model is suitable for interpretation (Fiss, 2011). Although the three identified configurations can be sufficient for the presence of iorg, these configurations are not necessarily the only solutions which might favor iorg. This outcome may also come from the presence of other conditions, and the QCA does not ignore that possibility. Nevertheless, the fact that three different configurations emerge from the analysis suggests that more than one pattern causes the situation of high iorg in EU regions. Furthermore, these pathways do not refer to only one condition but rather include a combination of factors which lead to the presence of iorg.

Table 3. Adequacy Analysis: Regions with "higher organizational innovation" (Presence of the outcome - Intermediate Solution)

\begin{tabular}{llll}
\hline & Raw & Unique & Consistency \\
& Coverage & Coverage & \\
\hline col*rdp* $^{*} \mathrm{edu}^{+}$ & 0.338036 & 0.051022 & 0.936450 \\
$\sim \mathrm{rural}^{*} \mathrm{col}^{*} \mathrm{rdb}^{*} \sim \mathrm{edu}+$ & 0.323665 & 0.045089 & 0.942780 \\
$\mathrm{rural}^{*} \mathrm{col}^{*} \mathrm{rdb}^{*} \mathrm{edu}+$ & 0.140804 & 0.049703 & 0.911263 \\
\hline
\end{tabular}

Solution coverage: 0.44

Solution consistency: 0.92

Note: $(\sim)$ absence of the condition. $(*)$ Logical operator $(+)$ Logical operator OR 
Configuration 1 is present in 16 EU regions with relatively low levels of population with tertiary education, relatively high rates of SME collaboration, and high public R\&D investment. Configuration 2 is present in another group of 16 regions which have in common that they are predominantly urban regions, have a presence of collaborating SMEs, high private R\&D investment and low levels of population with tertiary education. Configuration 3 is present in 7 regions, which are predominantly rural, have a presence of collaborating SMEs, high private R\&D investment, and a relatively high percentage of the population with tertiary education. Interestingly, configurations 1 and 2 both have low levels of population with tertiary education but collaboration among SMEs, and public R\&D spending (configuration 1), and private R\&D spending in predominantly urban regions (configuration 2) seem to compensate this fact. Configuration 3 shows that the rural context is suitable for iorg only in the presence of collaboration among SMEs, private R\&D investment, and a relatively high percentage of the population with tertiary education.

Figure 2 presents maps showing the regions included in the causal configurations and a map representing high iorg. Map 1 shows the regions with high organizational innovations; maps 2, 3, and 4 depict the regions that the three configurations obtained from the fsQCA explain; these configurations appear in combination in Map 5. Map 6 shows the regions which these configurations fail to explain.

Figure 2. Maps presenting the different configurations. 

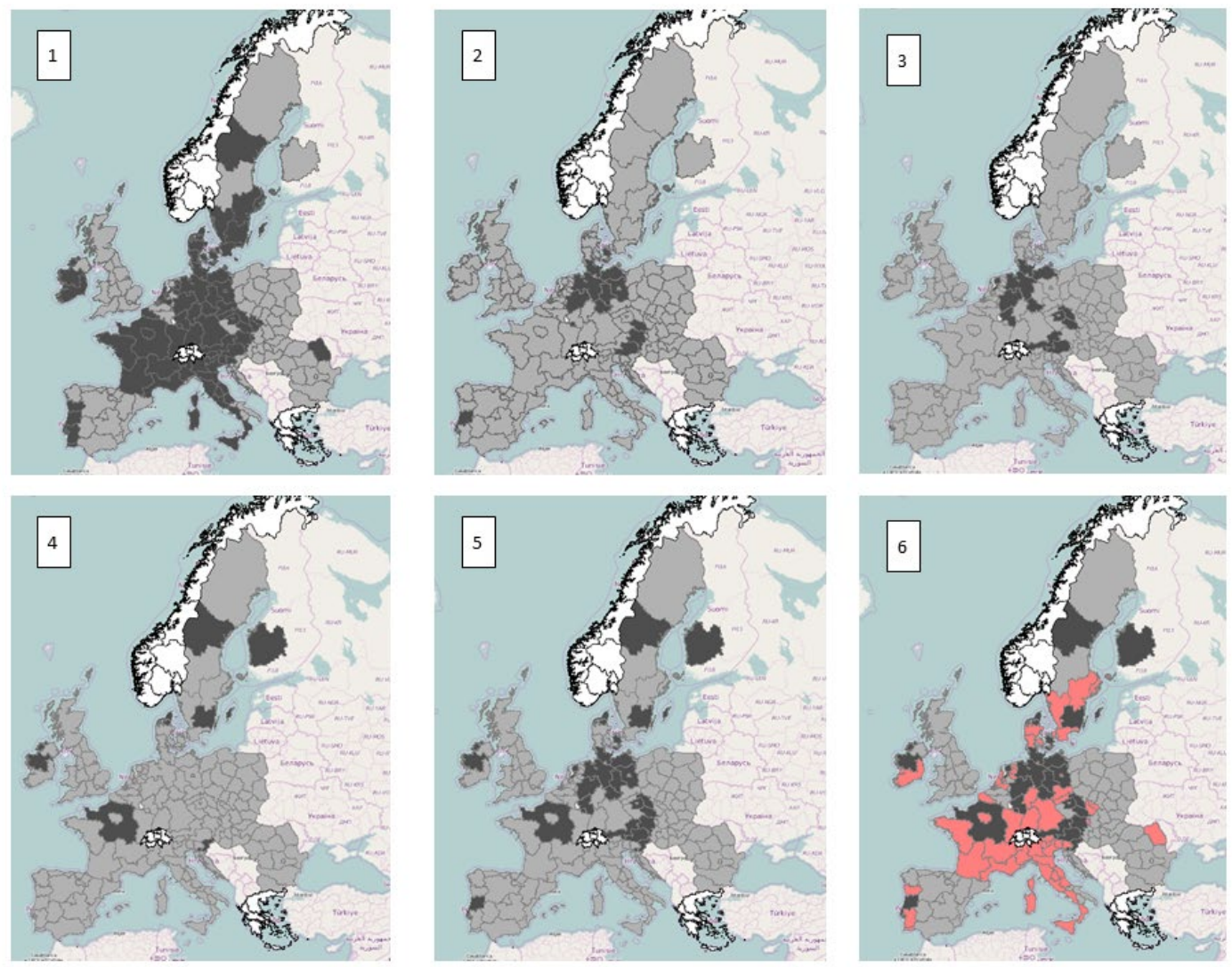

Absence I. Org

Casual Configuration

Unexplained

$\square$ No Data

\section{Discussion and conclusions}

The results raise four points in particular. First, no single necessary condition exists. Regarding the type of region, this finding shows that rurality or less dense population and levels of activity are not obstacles per se for a high percentage of organizational innovations. In other words, rurality is not a prohibitive obstacle to this type of innovation.

Second, two features emerge from configuration 1 from the fsQCA. On the one hand, this configuration suggests a combination of factors which lead to significant organizational innovation regardless of the type of region (in terms of ruralityurbanization). On the other hand, this configuration shows how, in regions with low 
levels of tertiary education, the combination of a high level of collaboration among SMEs and public investment in R\&D enables high rates of organizational innovation.

Third, although collaboration is not a necessary (in QCA terminology)

condition - because collaboration alone does not lead to high organizational innovation - this condition is present in all the configurations. This result supports proposition 2 in that collaboration creates an enabling culture substrate for-in this study - organizational innovations. These findings are particularly relevant to rural regions which, according to the literature, experience barriers to innovation, and confirm previous research in that rural areas with strong internal and external networks are more likely to grow (Terluin, 2003) and to promote learning and innovation (Ryser \& Halseth, 2010).

Finally, the results confirm (in line with propositions 3 and 4) the relevance of R\&D investment for organizational innovation at the regional level. Indeed, public investment (rdp) is present in configuration 1 which would be valid for any region regardless of that region being rural or urban. The theory section in this study discusses the link between public and private expenditure. Interestingly, the results show that the substitutability of public by private R\&D investment is valid only for urban regions. In the case of rural regions, a one-to-one substitution of this condition seems not to facilitate organizational innovation since private investment needs to appear in combination with high levels of tertiary education (compared to urban regions). Therefore, the proposition about the critical role of the availability of skilled labor to promote organizational innovation is valid only for rural regions. Both Table 2 on necessary conditions and Table 3 on selected configurations confirm that R\&D expenditure (either public or private) does not have the same impact on innovation in all EU regions, and that policies must consider other regional specificities (Crescenzi, 
2005). Thus, a “one-size-fits-all” regional policy would not be efficient (Capello \& Renzi, 2013).

The results of this research also suggest areas for further study. Future research should pay particular attention to the apparently contradictory role of the regional level of education (as measured on the Regional Innovation Scoreboard) in organizational innovation. In two of the three models, lower shares of tertiary education combined with other components (R\&D investment, SME collaboration), give rise to higher rates of organizational innovation. This study considers only organizational innovations, although other types of (technical) innovation may be present. A combined analysis could reveal how different types of innovations interact among themselves and with the education system. Future studies must also consider the relevance of different sector specializations in rural and urban regions. Future research could consider to what extent economic sectors dominating rural economies, combined with the presence of qualified workers, are likely to introduce organizational innovations, compared to urban areas where post-secondary education is a smaller determinant.

The analysis has some limitations. One of these is the geographical level of analysis and the classification of regions. NUTS2, particularly in some countries, are too large regions to adequately fit the dimensions of rural and urban regions. Working with NUTS3 would allow consideration of regions which are more homogeneous and to exploit existing regional classifications (see Naldi et al., 2015). However, this method would depend on the availability of data on innovation. Future analyses also could include other regional characteristics (e.g. the sectoral specialization of regional economies, or other measures of human capital) to better explain regional patterns of organizational innovation. Such analyses could focus on the regions identified in map 6 (Figure 2), that is, regions with higher rates of organizational innovation not sufficiently 
explained by the three models obtained from this study's fsQCA. A more detailed and individual analysis of the characteristics of these regions would be necessary to identify explanatory factors other than those resulting from this study's modeling exercise. 


\section{References}

Afonso, O. (2012). Diffusion and directed technological knowledge, human capital and wages. Economic Modelling, 3, 370-382.

Antonelli, C., Patrucco, P., \& Quatraro, A. (2011). Productivity growth and pecuniary knowledge externalities: An empirical analysis of agglomeration economies in European regions. Economic Geography, 87(1), 23-50.

Arrow, K. J. (1962). The economic implications of learning by doing. Review of Economic Studies 29(3), 155-173.

Audretsch, D., \& Keilbach, M. (2004). Entrepreneurship and regional growth: an evolutionary interpretation. Journal of Evolutionary Economics, 14(5), 605-616.

Bodman, P., \& Le, T. (2013). Assessing the roles that absorptive capacity and economic distance play in the foreign direct investment-productivity growth nexus. Applied Economics, 45(8), 1027-1039.

Bouncken, R. B., Pesch, R., \& Gudergan, S. P. (2015). Strategic embeddedness ofmodularity in alliances: Innovation and performance implications. Journal of Business Research, 68(7), 1388-1394

Camagni, R., \& Capello, R. (2013). Regional competitiveness and territorial capital: a conceptual approach and empirical evidence from the European Union. Regional Studies, 47(9), 1383-1402.

Caselli, F., \& Coleman, W. J. (2006). The world technology frontier. American Economic Review, 96(3), 499-522.

Castrogiovanni, G. J., Domenech, J., \& Mas-Verdú, F. (2012). Variations in SME characteristics and the use of service intermediaries for R\&D. Canadian Journal of Administrative Sciences 29(2), 154-164 
Chesbrough, H. (2003). Open innovation: The new imperative for creating and profiting from technology. Boston: Harvard Business School Press Books.

Ciccone, A., Papaioannou, E. (2009). Human capital, the structure of production and growth. The Review of Economics and Statistics, 91(1), 66-82.

Coe, D. T., Helpman, E., \& Hoffmaister, A. W. (2009). International R\&D spillovers and institutions. European Economic Review 53, 723-741

Cohen, W. M., \& Levinthal, D. A. (1989). Innovation and learning: The two faces of R \& D. The economic journal, 99(397), 569-596.

Cooke, P., Asheim, B., Boschma, R., Martin, R., Schwartz, D. \& Tödtling, F. (Eds) (2011). Handbook of regional innovation and growth. Cheltenham: Edward Elgar.

Crescenzi, R. (2005). Innovation and regional growth in the Enlarged Europe: The role of local innovative capabilities, peripherality, and education. Growth and Change, 36(4), 471-507.

Creszenzi, R., \& Rodriguez-Pose, A. (2011). Innovation and regional growth in the European Union. Springer.

David, P. A., Hall, B. H., Toole, A., A. (2000). Is public R\&D a complement or substitute for private R\&D? A review of the econometric evidence. Research Policy 29, 497-529.

Doloreux, D., \& Dionne, S. (2008). Is regional innovation system development possible in peripheral regions? Some evidence from the case of La Pocatiére, Canada. Entrepreneurship \& Regional Development, 20, 259-283

Duranton, G., \& Puga, D. (2004). Micro-foundations of urban agglomeration economies. Handbook of regional and urban economics, 4, 2063-2117. 
Escribano, A., Fosfuri, A., \& Tribó, J (2009). Managing external knowledge flows: The moderating role of absorptive capacity Research Policy, 38(1), 96-105.

European Commission (2014). Regional Innovation Scoreboard. http://doi.org/10.2769/88893.

EUROSTAT (2010). Eurostat regional yearbook 2010. Brussels

Fabrizio, K. R. (2009). Absorptive capacity and the search for innovation Research Policy 38(2), 255-267.

Fiss, P. (2009). Case studies and the configurational analysis of organizational phenomena. In C. Ragin, \& D. Byrne, Handbook of case study methods (424440). Thousand Oaks, CA: Sage.

Fiss, P. (2011). Building better causal theories: A fuzzy set approach to typologies in organization research. Academy of Management Journal, 54(2), 393-420.

Garcia-Alvarez-Coque, J. M., Mas-Verdu, F., \& Sanchez García, M. (2015).

Determinants of Agri-food Firms' Participation in Public Funded Research and Development. Agribusiness, 31(3), 314-329.

Guillaume, R, Doloreux, D. (2011). Production systems and innovation in 'satellite' regions: Lessons from a comparison between Mechanic Valley (France) and Beauce (Québec). International Journal of Urban and Regional Research, 35(6), $1133-53$.

Hagedoorn, J. (2002). Inter-firm R\&D partnerships: an overview of major trends and patterns since 1960: Research Policy, 31, 477-492.

Hall, R. E., \& Jones, C. I. (1999). Why do some countries produce so much more outputper worker than others. The Quarterly Journal of Economics, 114(1), 83116. 
Hanushek, E. A., Woessmann, L. (2012). Schooling, educational achievement, and the Latin American growth puzzle. Journal of Development Economics, 99(2), 497512.

Howells, J. (2006). Intermediation and the role of intermediaries in innovation. Research Policy, 35, 715-728.

Huggins, R. (2003). Creating a UK competitiveness index: regional and local benchmarking. Regional Studies, 37(1), 89-96.

Huggins, R., \& Johnston, A. (2009). Knowledge networks in an uncompetitive region: SME innovation and growth. Growth and Change, 40(2), 227-259

Inkinen,T., \& Suorsa, K. (2010). Intermediaries in regional innovation systems: Hightechnology enterprise survey from Northern Finland. European Planning Studies, 18(2), 169-187.

Justman, M., Teubal, M. (1991). A structuralist perspective on the role of technology in economic growth and development. World Development, 19(9), 1167-1183.

Kline, S. J., \& Rosenberg, N. (1986). An overview of innovation, in Landau, R. and Rosenberg, N. (Eds.). The positive sum strategy: Harnessing technology for economic growth. Washington, DC: National Academy Press.

Lasagni, A. (2012). How can external relationships enhance innovation in SMEs? New evidence for Europe. Journal of Small Business Management, 50(2), 310-339.

Lin, C., Wu, Y. J., Chang, C., Wang, W., \& Lee, C. -Y. (2012). The alliance innovation performance of R\&D alliances - The absorptive capacity perspective. Technovation, 32(5), 282-292.

Misangyi, V., \& Abhijith, G. A. (2014). Substitutes or complements? A configurational examination of corporate governance mechanisms. Academy of Management Journal, 57(6), 1681-1705. 
Naldi, L., Nilsson, P., Westlund, H., \& Wixe, S. (2015). What is smart rural development? Journal of Rural Studies, 40, 90-101.

O’Mahony, M., \& Vecchi, M. (2009). R\&D, knowledge spillovers and company productivity performance. Research Policy 38(1) 35-44.

Prahalad, C. K., \& Ramaswamy, V. (2004). The future of competition: Co-creating value with customers. Harvard Business School Press, Boston.

Ragin, C. (1987). The comparative method: Moving beyond Qualitative and Quantitative Methods. Berkeley: University of California.

Ragin, C. (2006). Set relations in social research: Evaluating their consistency and courage. Political Analysis, 14(3), 291-310.

Ragin, C. (2008). Redesigning social inquiry: Fuzzy sets and beyond (Vol. 240). Chicago: University of Chicago Press.

Ragin, C., \& Fiss, P. (2008). Net effects analysis versus configurational analysis: An empirical demonstration. In C. Ragin, Redesigning social inquiry: Fuzzy sets and beyond (190-212). Chicago: University of Chicago Press.

Roig-Tierno, N., Alcázar, J., \& Ribeiro-Navarrete, S. (2015). Use of infrastructures to support innovative entrepreneurship and business growth. Journal of Business Research, 68(11), 2290-2294.

Ryser, L. \& Halseth, G. (2010). Rural economic development: A review of the literature from industrialized economies. Geography Compass, 4-6, 510-531.

Schneider, C., \& Wagemann, C. (2010). Standards of good practice in Qualitative Comparative Analysis (QCA) and fuzzy-sets. Comparative Sociology, 9(3), $397-418$

Schneider, M. R., Schulze-Bentrop, C., \& Paunescu, M. (2010). Mapping the institutional capital of high-tech firms: A fuzzy-set analysis of capitalist variety 
and export performance. Journal of International Business Studies, 41(2), 246266.

Terluin, I. J. (2003). Differences in economic development in rural regions of advanced countries: An overview and critical analysis of theories. Journal of Rural Studies, 19(3), 327-344.

Un, C. A., \& Asakawa, K. (2015). Types of R\&D collaborations and process innovation: The benefit of collaborating upstream in the knowledge chain. Journal of Product Innovation Management, 32(1), 138-153.

Vandenbussche, J., Aghion, P., Meghir, C. (2006). Growth, distance to frontier and composition of human capital. Journal of Economic Growth, 11, 97-127.

Vargo S. L, \& Lusch, R. F. (2008). Service-dominant logic: Continuing the evolution. Journal of the Academy of Marketing Science, 36(1), 1-10

Woodside, A., \& Zhang, M. (2012). Identifying X-consumers using causal recipes: "Whales" and "Jumbo Shrimps" Casino Gamblers. Journal of Gambling Studies, $28(1), 13-26$.

Wu, J. (2014). Cooperation with competitors and product innovation: Moderating effects of technological capability and alliances with universities. Industrial Marketing Management, 43(2), 199-209. 